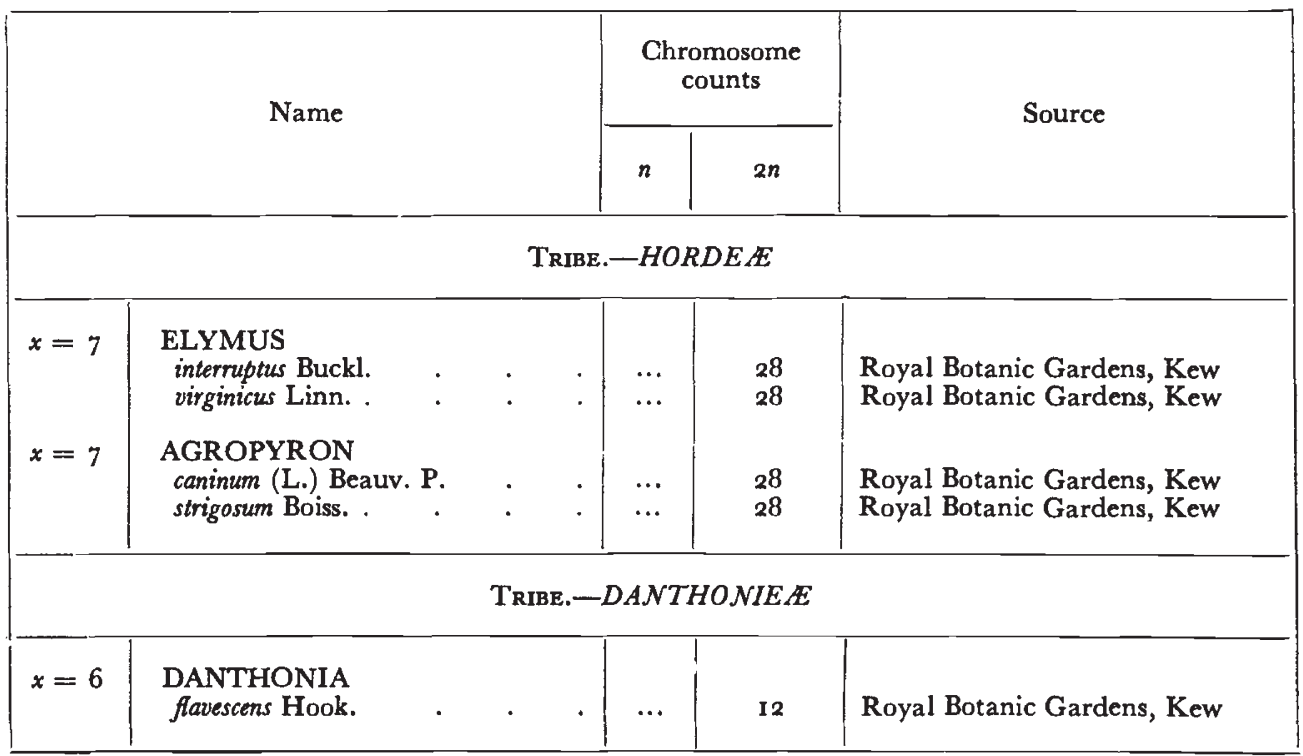

\title{
REFERENCES
}

SINGH, D. N., AND GODWARD, M. B. E. Ig6o. Cytological studies in the Gramineæ.

Heredity, 15, 193-197.

CLAYTON, W. D. 1962. Studies in the Graminex II. Kew Bull., 16, 248-250.

\section{MUTUAL REDUCTION OF DOMINANCE INVOLVING THREE LOCI IN MUS MUSCULUS}

JEAN A. H. TATCHELL

Department of Genetics, University of Cambridge

Received 3o.v.63

When the heterozygote becomes phenotypically distinct from the dominant homozygote due to the presence of a mutant gene at a second locus, reduction of the dominance of the first gene can be said to have taken place. This phenomenon was first noticed in mice in I9I I by Durham, who observed that $B B$ became distinct from $B b$ when on a pink-eye $(p p)$ background, and again in 193 I by Snell. However, it was not until 1953 that Wallace showed this reduction to be mutual, $P P$ and $P p$ being distinguishable from each other when on a $b b$ background, thus giving rise to six distinct phenotypes instead of the expected four (table $r$ ).

Goodwins (1958) further showed that on a dilute $(d d)$ background the 
reduction of dominance was increased and two more phenotypic classes were distinguishable (table 2).

As Goodwins' experiment did not cover the complete range of genotypes it seemed desirable to repeat Wallace's experiment on a $d d$ background, thus duplicating and extending Goodwins' work.

TABLE I

The distinguishable phenotypes resulting from interaction of $\mathrm{p}$ and $\mathrm{b}$ in a +DD genotypes (from Wallace, r953)

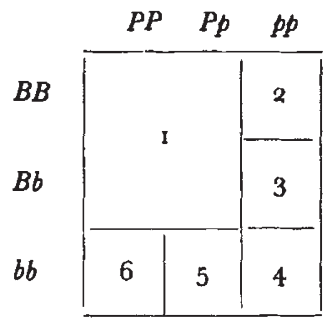

All nine genotypes with respect to $P-p$ and B- $b$ were bred on a homozygous dilute, non-agouti ( $d d a a$ ) background, and ten mice for skinning were taken from non-segregating litter of each genotype.

Before any conclusions were drawn from the results the median skins of each genotype were chosen as follows. The ten skins within a genotype

TABLE 2

Distinguishable phenotypes resulting from interaction of $\mathrm{p}$ and $\mathrm{b}$ in aa dd genotypes (after Goodwins, 1958)

\begin{tabular}{c|c|c|}
\multicolumn{1}{c|}{} & \multicolumn{1}{c|}{$P P$} & \multicolumn{1}{c}{$P p$} \\
\cline { 2 - 3 }$B b$ & $\mathrm{I} C$ & $\mathrm{I} d$ \\
\hline$b b$ & 6 & 5 \\
\hline & & \\
\hline & & \\
\hline
\end{tabular}

were set out in a random order and from five to seven observers were asked to arrange them in order of intensity, this being done for all genotypes. Most observers agreed on the two or three darkest and lightest skins within each genotype, but there was disagreement about the correct positions that should be allotted to the other skins. The skin chosen to represent the genotype was that which most observers placed fifth or sixth in the series. At the same time each observer was asked to comment on the amount of colour variation within each genotype.

The nine skins were set out as in table 3 in order that comparisons between genotypes could be made.

The $b b p p$ genotype (4) is phenotypically distinct from all others, but the distinction observed by Wallace between the genotypes 2 and 3 and between the genotypes 5 and 6 when homozygous for $D$, is much smaller in the presence of $d d$, and 2 and 3 are here almost indistinguishable. Of the remaining four genotypes, $\mathrm{I} a$ and $\mathrm{I} d$ are distinct from $\mathrm{I} b$ and $\mathrm{I} c$, although indistinguishable from each other. Thus the phenotype I becomes three phenotypes in the presence of $d d$, which corresponds with the number of 
recessive genes present. The presence of $d d$ appreciably diminishes the dominance of $B$ and $P$ in the doubly dominant phenotype, but not in the others.

These results are in complete agreement with those of Goodwins and are not dissimilar to those of Wallace when the large effect of $d d$ on the intensity of coat colour is considered. The inability of the naked eye to

TABLE 3

Designation of genotypes combining $\mathrm{p}$ and $\mathrm{b}$ with aa $\mathrm{dd}$

\begin{tabular}{|c|c|c|c|}
\hline & $P P$ & $P p$ & $p p$ \\
\hline$B B$ & Ia & $\mathrm{I} b$ & 2 \\
\hline$B b$ & $\mathrm{I} c$ & Id & 3 \\
\hline$b b$ & 6 & 5 & 4 \\
\hline
\end{tabular}

distinguish between subtle shades when two pale colours are compared probably accounts wholly for the apparently greater reduction of dominance with $b b P p$ than with $B b p p$. This point is emphaised by the fact that the darker genotypes ( $1, \mathrm{I} b, \mathrm{I} c, \mathrm{I} d, 6)$ were considered to be the most variable by the observers asked to grade them, and one or two observers found it impossible to arrange the skins within the paler genotypes as there was so little apparent variation. Several of the genotypes overlapped at the extreme end of their range, and, as suggested by Wallace (1953), selection in a suitable stock could probably enhance or suppress the interaction.

Many examples of interaction, where the double recessive animal shows a more than additive response to the genes present, have been found in laboratory organisms ranging from flies to mice but reduction of dominance is a more rarely studied phenomenon and the possible reciprocality of this effect has often been neglected. It is a matter of interest as it can give material for the study of the possible mechanism of evolution of dominance and Fisher ( $\mathrm{I} 93 \mathrm{I}$ ) postulated that the mutant becomes completely recessive in its normal genotypic environment. In unnatural situations, such as the simultaneous presence of three mutants, this acquired recessiveness is disrupted in an unpredictable manner and appears to approximate to a dosage effect. Reduction of dominance is a phenomenon that has not been fully studied by itself, most known examples having turned up in experiments designed for other purposes. More deliberate study of the phenomenon should add to our understanding of the mechanism of dominance and its evolution.

\section{REFERENCES}

DURHAM, F. M. 19II. Further experiments on the inheritance of coat colour in mice. 7. Genet., $I, 159^{-1} 7^{8}$.

FISHER, R. A. 1931. The evolution of dominance. Biol. Revs., 6, 345-368.

GOODWINs, I. R. 1958. A further case of dominance interaction in Mus musculus. Heredity, 12, 73-75.

SNELL, G. D. 1931. Inheritance in the house mouse. Genetics, $16,42-74$.

WALLACE, M. E. 1953. A case of mutual reduction of dominance: observed in Mus musculus. Heredity, 7, 435-437. 